\title{
Strategy Integration at the Global Level
}

\subsection{Main Points of This Text and Remaining Topics}

This chapter uses case studies of management strategy for effective global level operations to discuss how companies from advanced nations can incorporate emerging countries experiencing rapid growth into their operating processes. There are two approaches to corporate strategy theory for maintaining sustainable competitive advantage against competitors over time: an approach focused on management resources held by the company (Barney 1986, 1991), and on a theory of positioning that analyzes the competitive environment of a market to select the optimal position (Porter 1980). Extrapolating these corporate strategies to a global level requires an awareness of national barriers. While the earth may be becoming flatter, there are still significant economic and institutional gaps between advanced and emerging countries.

The world, while appearing to be flat, still is somewhat rough due to national borders. Companies must make careful strategic decisions as to whether they will adapt to the local conditions of each market or pursue the benefits of scale in overseas markets through aggregation using products made for global markets. In addition, companies can use the above methods in combination with arbitrage, which leverages the gaps that exist between countries (see the explanation of the AAA framework in Chap. 2 for more details). The business environment in emerging countries is rapidly changing, so companies must not only use their own resources but must also consider partnerships with local companies to respond flexibly (see the explanation of strategic alliances in Chap. 7). Furthermore, in order to be successful in the markets of emerging countries while going head to head with local competitors, companies from advanced nations with a technological advantage must formulate a technology management strategy and an appropriate marketing strategy catering to the local market. These basic concepts are discussed in Chaps. 9 and 11.

So far, our discussions have examined the strategy to be adopted for specific countries, with a particular focus on China and India. This is because the differences 
between domestic and global businesses are in terms of the operating environments that differ greatly by country, and it is appropriate for us to deal with examples that are as specific as possible, while keeping our target countries in mind. In particular, in Japan, with a homogeneous social structure focused on the Japanese, it can be difficult to be acutely aware of these differences. In Chap. 4, we explained the political and business conditions in China and India, and included an overview of the economic progress made by each country. By using these case studies, it is hoped that the reader will understand the detailed context of the business environments in each country and be aware of the differences between these countries.

For global corporations, however, these country-by-country explications must ultimately be integrated into one overall business strategy. In doing so, companies must investigate the function of the headquarters, which so far have been rather vague. The company headquarters is the node that ties together various overseas entities within a global corporation and exploits synergies between the activities of these entities. In Chap. 2, we used an I-R grid to explain the theory of balance between global integration at the headquarters and adaptation through local entities. It is easy to imagine that this balance will vary with the peculiarities of the countries in which these entities lie, but as a company becomes conscious of the diversity within these overseas companies, what form of organization should the company deploy overall? As our last remaining topic, we discuss strategy integration at the global level on the basis of our discussions to this point.

\subsection{Knowledge Management in Global Corporations}

For global companies, company-wide knowledge management is an important function of the headquarters. The term headquarters as used herein refers not to the company organization (groups indirectly connected to operations, such as HR, accounting, or legal) but rather the core of global operations that exist in a home country (in this case, Japan). For example, a company's "mother factory" has the most advanced technology and is the core of manufacturing technology. When expanding manufacturing overseas, companies typically transfer production equipment and processes, as well as worker procedural manuals and other know-how from this mother factory to the new overseas factory. When launching the overseas factory, companies send many people specializing in production technology from the home country to provide instruction. Companies that offer low wages must, to a certain extent, adapt to local conditions, and in some cases perform tasks manually that would otherwise be machine operated in the home country, despite the typical flow of knowledge from the home country (e.g., a mother factory) to the local factory. However, work procedures within factories are constantly being improved as part of total quality control (TQC), and in case a local factory discovers better ways of performing tasks, it will be spread across the company via the headquarters.

The headquarters takes a leading role in product development, since personnel, technology, intellectual property (IP), and product development know-how reside there. For example, for products in which the production process must be considered 
in the product development phase, some level of work can be done overseas, since certain countries will have a production function. The automotive industry is a typical example of this, and Japanese manufacturers have created manufacturing centers with a certain amount of scale in Europe and the US. Recently, steps have been taken to create manufacturing facilities in emerging countries such as China, Thailand, and India. Wages in these countries are low, thereby allowing companies to reduce their development costs by operating there. In either case, development centers at the headquarters play a central role, and knowledge flows from the headquarters to the overseas facilities. However, as can be seen in the reverse innovation examples of Chap. 11, in certain cases, companies can develop new products at facilities in emerging countries, expand sales to other emerging countries, and even sell these products in the home country. In these cases, knowledge creation is facilitated in the local markets, which is fed back to the home country, thereby creating a reverse knowledge flow.

The headquarters plays an important role as the central node in a global corporation to control the company-wide flow of information so that the necessary knowledge can be put to use where it is needed. This information flow is not limited to the internal corporation. Production divisions have relationships with equipment manufacturers, product development divisions work with parts and materials manufacturers, research divisions partner with universities and their counterparts in other companies, and information is exchanged on a daily basis with all of these external organizations. Knowledge obtained from external overseas partnerships is incorporated within all relevant local entities, but some of this information should be shared across the company, which is the role of the headquarters. As we consider these external relationships, maximizing the internal information flow is not necessarily the best course of action. In these exchanges with external parties, companies should avoid leaking important technologies and information that are key to competitive advantage. Technology information control is important in keeping these so-called technology leaks from becoming detrimental. The strict implementation of policies to stop leaks and ensuring that all employees are aware of them is the responsibility of the headquarters. Companies may find it necessary to decouple information sources internally in an effort to limit access to important information to certain employees.

Companies must also keep in mind the costs associated with knowledge transfer. For example, in the production technology case discussed above, the mother factory is aware of the different types of production equipment and production processes, and maintains the work procedure manual. But in reality, there is also a great deal of implicit knowledge, requiring companies to send specialists on-site from the mother factory to provide instruction. In addition, companies can provide appropriate training required by local factory workers depending on their skills and knowledge. These expenses cannot be ignored. Within the field of business management, companies are defined as organizations that hold knowledge accumulation and the "knowledge-based theory of the firm" (Kogut and Zander 1992) defines the efficiency of knowledge propagation within an organization as an organizational capability. In this theory, the costs of knowledge propagation is said to correlate with low 
codifiability, high complexity, and low teachability. However, overcoming these obstacles and facilitating information flow within an organization is a paradox because the process can be easily imitated by competitors. Accordingly, combinative capabilities (Kogut and Zandar 1992), which create new innovation in conjunction with existing knowledge, are important from the perspective of a company's sustained competitiveness. A global company's headquarters incorporates the new knowledge required to expand in each country from the production, development, and research functions, in addition to domestic knowledge, and plays a key role in integrating this knowledge and strengthening operations.

Most case studies in this text have been examples of companies from advanced countries expanding to emerging countries. In these cases, the business environments between the two countries are vastly different, thereby lowering the ease of propagation, resulting in an increase in the information propagation costs. When creating wholly owned subsidiaries, companies hire local employees with high potential and can expect efficient operations with the help of proper training. However, this is incredibly difficult for companies that enter via joint ventures with local companies because of the necessity to bring together knowledge from two organizations. Thus, for operations expanding overseas with high costs of knowledge transfer, a wholly owned subsidiary is generally a more efficient option (Kogut and Zander 1993). On the other hand, because companies expanding overseas via a partnership with a local company face great difficulties, if a company can develop the ability to effectively manage the partnership, they may realize tremendous competitive advantage. Companies must gain experience with international alliances, including those entered into with companies from emerging countries, create a knowledgebase, and then leverage that knowledge in new projects. By developing an alliance management capability, as described in Chap. 7, companies will find themselves with a greater range of options that will be important for them as they set global strategies using wholly owned subsidiaries or joint ventures.

\subsection{Diversity in Overseas Entities}

Creating strategy integration at the global level requires an understanding of the diversity among a company's overseas entities, as corporate-wide knowledge management implemented by the headquarters varies depending on the activities in each overseas base. For example, companies that conduct R\&D overseas can use homebase augmentation (HBA), which increases the IP in the home country by incorporating the latest technology from local markets, or home-base exploitation (HBE), which creates new overseas markets on the basis of technology from the home country (refer to Chap. 11 of this paper for more details). In the case of Japanese companies, those that conduct research in Silicon Valley or form partnerships with local universities and high tech ventures are examples of the former, while locally developing consumer electronics products tailored to the Chinese market corresponds to the latter. The former focuses on incorporating knowledge as part of headquarters knowledge management and is discerning of knowledge as a necessary 
capability to that end. On the other hand, the latter case takes core technology required for local development and pours it into local entities, making it important to understand a broad range of company-held technologies. In other words, the capabilities required by the headquarters vary with R\&D objectives, and companies cannot respond by using homogeneous personnel or the knowledge management method.

The diversity of overseas entities is due to the differences in socioeconomic circumstances in target countries. There are major differences between environments in advanced and emerging countries, but as shown in Chap. 4's comparison of China and India, a great diversity within emerging countries is also evident. Using the example of $R \& D$ centers, activities may differ because of a multitude of factors such as technology levels of universities and companies in the target country, number of skilled engineers and average wages, and IP systems. In addition, the competitive environment in local markets has a major impact on the management of local entities. If a local entity has already created a competitive position relative to competitors, the headquarters does not need to intrude on the local entity. However, if that is not the case and if strategic priority is high in the target country, the headquarters must shore up whatever strategic advantages the home country may have.

Table 15.1 summarizes the varieties of local bases and the differences in management of the local entities. The vertical axis indicates the differences in operating environments between home and target countries, while the horizontal axis indicates the level of relative competitiveness of the local entity. This chart is inspired by that of Bartlett and Ghoshal (1989) that indicates the strategic importance of a target country on the vertical axis and the distances according to the CAGE framework (see Chap. 2). In addition, it conforms to this text, which focuses on global strategy for emerging countries. In the case of small differences in operating environments, companies can choose normal management strategies regardless of national borders. In other words, in case of high competitiveness among local entities, companies must learn the reason behind that strength and leverage it within the headquarters, whereas if strengthening the local entity becomes necessary, then the headquarters must take the lead.

A problem arises in cases where differences in operating environment between advanced and emerging countries are large. First, in case of high local entity competitiveness, companies should allow local entity autonomy in its operations. However, headquarters must not provide a completely free rein but rather analyze

Table 15.1 Comparison of overseas subsidiary by type

\begin{tabular}{l|l|l}
\hline & High local entity competitiveness & $\begin{array}{l}\text { Low local entity } \\
\text { competitiveness }\end{array}$ \\
\hline $\begin{array}{l}\text { Small differences in operating } \\
\text { environment compared with } \\
\text { home country }\end{array}$ & Learning from local entity & $\begin{array}{l}\text { Shoring up local operation } \\
\text { by the headquarters }\end{array}$ \\
\hline $\begin{array}{l}\text { Large differences in operating } \\
\text { environment compared with } \\
\text { home country }\end{array}$ & $\begin{array}{l}\text { Roll out of autonomous } \\
\text { operations and globalization of } \\
\text { local entity }\end{array}$ & $\begin{array}{l}\text { Partnerships with local } \\
\text { companies }\end{array}$ \\
\hline
\end{tabular}


the strengths of the local entity and reference that example in other target countries with similar operational environments - a global roll out. On the other hand, companies find it difficult to respond in case of low local entity competitiveness. Because local circumstances are different from those in the home country, the likelihood of making improvements through efforts led by the headquarters is low. In this case, it is more effective for companies to form partnerships with local companies, thereby enabling a better understanding of the business environment in the target country and an analysis of any failures.

Major Japanese manufacturers typically have multiple overseas operations. In addition to Europe and the US, they have entities in China and Southeast Asia. Many of these companies also have operations in India, South and Central America, and other areas. Corporate strategies differ according to prioritized regions, but from the perspective of risk dispersion, companies are not likely to choose an overseas strategy that centralizes operations in one location. Thus, headquarters must account for a variety of circumstances in the management of its overseas operations. According to the classifications listed in Table 15.1, the size of differences in operating environments with the home country affects the skills required in the headquarters function. Particularly where there are large differences in the operating environment, companies must think of flexibility in regard to the local entity. The one-way management of knowledge flow from the headquarters to the local entity that is typical in Japan does not work well. Global strategies should not be homogeneous across an entire company but must share an awareness of regional and national diversity at the top levels of the company.

\subsection{Organizational Structure Within Global Corporations}

What type of organization is best for a company that wants to operate diverse local entities efficiently company-wide? Recall the balanced circle of authority for headquarters and local entities according to the I-R grid explained in Chap. 2. Companies can be classified into organizations that operate homogenously across the world with headquarters taking the lead (global corporations typical in Japan), organizations with groups of companies in each country (multinationals, typical in Europe), and international organizations in between (typically seen in the US). Figure 2.7 of Chap. 2 also described another type of organization - the transnational. This organization combines global integration with local responsiveness.

Transnational corporations were described by the creators of the I-R grid, Bartlett and Ghoshal, as being ideal (Bartlett and Ghoshal 1989). This type of organization maintains local entity diversity while maintaining company-wide efficiency in increasing global learning ability. This chapter's discussions on the role of the headquarters in strategy integration as has been previously described are based on discussions of this learning ability. However, the book authored by Bartlett and Ghoshal was published in the 1980s, during which discussions on multinational corporations focus on the advanced regions of Japan, the US, and Europe. In today's world, emerging countries are on the rise, and the focus of global business is transitioning 
from advanced countries to newly developing countries such as China and India. Thus, companies must integrate strategies regarding organizational structure for global companies to account for advanced countries as well as local entities with completely different business environments. A perspective of globalization rollouts and partnerships with local companies is required, as is shown in Table 15.1. In other words, in addition to a mindset focusing on the headquarters, as is assumed by transnational organizations, companies will require strategies in the basis of local entities as well. However, the two must not be combined irrationally. Companies must accept diversity and include variation within their strategies.

Metanational corporations have organizational structures that eliminate all concepts of the headquarters in global corporations (Doz et al. 2001). The concept truly transcends the "state." Asakawa (2011) cites STMicroelectronics (Italy and France) and Nokia (Finland) as examples of metanationals. Neither of these companies have large markets in their home countries. Specifically because they are "companies born in the wrong place," they have built up competitive strengths that do not rely on nationality, and accrue technology from throughout the world. However, this concept has its limitations. Asakawa (2011) raises seven problems, and among them, the underestimation of knowledge propagation costs is critical. As we have heretofore explained, there is much implicit knowledge among the total knowledge required to run a company and its cost of propagation is significant. Technology cannot be freely transferred from overseas only because a home country does not have one. It is economically rational for global companies to have a home country concept to gather knowledge in one place.

In a related area, it is worth noting the "hollowing out" of industries that often accompanies the globalization of business activities. Despite the national barriers, it is evident that the world is becoming flatter. In the process, business activities will become global as a matter of economic rationale. There are an increasing number of companies taking high value added activities, such as R\&D, in addition to transferring production overseas. However, as we have seen throughout this text, while overseas R\&D activities can take on diverse forms, they increase the competitiveness of the company on an overall basis by strengthening cost structures and overseas markets. Thus, viewing this as an issue of hollowing out is incorrect. Most IP and know-how used in R\&D, as well as intangible assets that are sources of corporate value, including technology embodied in personnel, are stored as implicit knowledge, and carry with it costs when transferred across international borders. Accordingly, it makes economic sense to keep core knowledge in a company's home country. In that sense, the overseas expansion of Japanese companies has not resulted in a hollowing out. Rather, by establishing overseas R\&D centers, companies can take excellent local technology and ideas for innovation, and make the home country knowledgebase much stronger. According to the results of an international survey comparing the activities of the R\&D centers of Japanese, European, and US companies in China, Japanese companies have been slower than their Western competitors in forming partnerships with local universities and companies (Motohashi 2011). The opportunities presented by globalization are available to Japanese companies and their competitors from Europe and the US in equal 
measure. Note that in case of movements to obstruct the globalization of Japanese companies because of a belief in a hollowing out, they will become an impediment to the international competitiveness of these Japanese companies, and there is an extreme danger of this damaging the national economy.

We return to the main topic of this chapter-optimal organizational structures for global corporations. As has been heretofore explained, while theories abound on the matter, currently nothing conclusive has been found in academic literature. Global business environments are becoming increasingly complex because of the rise of emerging countries, and perhaps the reality is that diversity makes it impossible to explain it using a single model. Nevertheless, if one direction is to be proposed, we believe that the middle path between hierarchical and network organizational structures is optimal. Figure 15.1 shows both schematics of these organization types.

The hierarchical structure centers on the headquarters and can be seen in many multinational companies with multiple local entities. Companies can be classified as global, international, or multinational, according to the I-R grid, and depending on the level of authority granted to local entities by the headquarters. The hierarchical structure concentrates core management resources and knowledge at the headquarters, with the local entities working on that model, and assumes a one-way flow of knowledge from the headquarters to the local entities. In contrast, a network structure does away with the lord-retainer relationship between the headquarters and local entities, and connects global entities in the form of a network. From the perspective of accountability to stakeholders, this type of corporate organization is impossible, but is discussed to explain the hybrid organization. However, the
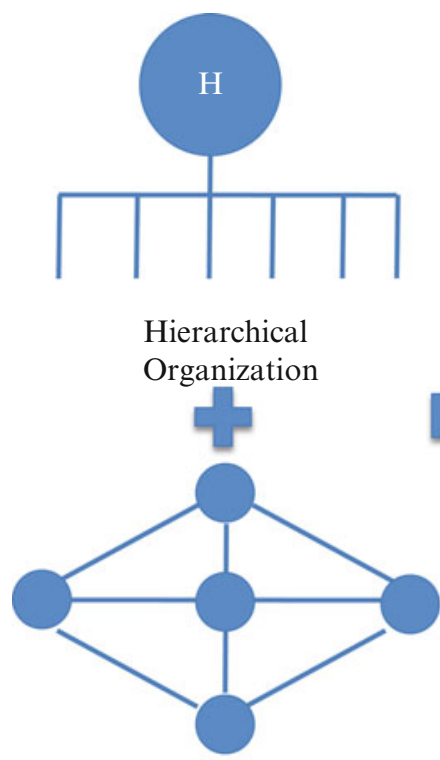

Network Organization

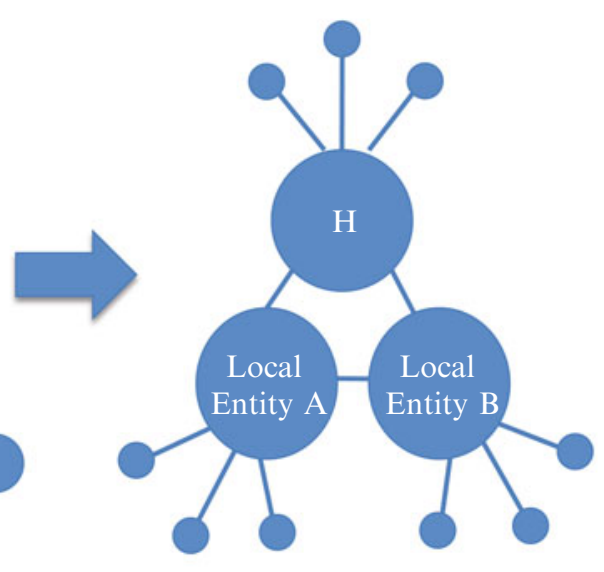

Hybrid Organization

Fig. 15.1 Comparison of organization of global corporations 
concept of a metanational corporation that does away with the idea of a home country is similar in structure to the hybrid organization.

When viewing companies as entities that create and capture knowledge at the global level to innovate from their union, both the hierarchical and network structures have their own failings. First, the hierarchical structure does not make use of activities to create and capture knowledge within local entities. As we have repeatedly stated throughout this text, there is a strong likelihood of successes in the home country not being extendable to local markets due to the primary battlegrounds of global businesses shifting to emerging countries, where business environments are vastly different from advanced countries. In this case, local knowledge is critical, as in the case of reverse innovation. On the other hand, network structures have more links (connecting bases) than the number of nodes (number of bases), making information propagation costs prohibitively expensive. It also includes the fundamental problem of having unclear decision-making mechanisms for the overall company.

Accordingly, in regions with business environments significantly different from that in the home country, companies should select structures that establish regional centers bundling a certain number of bases and manage these regional centers at the headquarters. As indicated in Fig. 15.1, a network structure has headquarters and regional centers, and a hybrid structure has a hierarchical structure for the remainder. However, as the number of regional centers increase, the information propagation costs within the core network increase. Thus, these regional centers should be kept to the absolute minimum. The key point is that the headquarters and the regional centers are connected by the network structure. If we move this to a hierarchical structure of the headquarters dictating to regional centers, then we face a high likelihood of worsened efficiency compared to a headquarters-centered organization, from the perspective of information processing ability. In regional centers with business environments that differ from that in the headquarters, companies should prioritize the flow of knowledge from regional centers to headquarters by granting the regional centers a certain level of autonomy. Also, within the core network organization, it is important for companies to work on strategy selection and execution, with an awareness of diversity within the overall corporate business strategy.

\subsection{Conclusion}

In summary, we have explained ways to manage diverse overseas entities from the perspective of corporate knowledge management, using the issue of the overall integration of global strategies. According to the lifecycle theory in terms of globalization of corporate activities, companies can begin by exporting parts and services, then move each part of the corporate value chain, such as procurement, production, and sales, to overseas entities, and then create integrated entities that include R\&D functions. Many large corporations in advanced countries, including those in Japan, have already reached this final stage, and have reached a point of maturity in regard to globalization within advanced countries. In addition, the rise of emerging countries such as China and India in recent years has been dramatic, and considerable 
investments have poured into these countries. Among the changes in business environments within global corporations, increasing importance has been given to the bi-directional flow of knowledge that considers the heterogeneity of local entities and incorporates local innovation across the company, rather than the one-way flow of information from headquarters to local entities. As a result, we state that organizational structures for global corporations should move from hierarchical structures with the headquarters at the center, to a hybrid structure (i.e., a fusion of a hierarchical structure and a network structure) that centers on a core network of the headquarters and important regional centers.

We conclude this chapter by discussing the issues of diversity and flexibility in management strategy. In this chapter, we repeatedly declared the importance of creating strategies in response to business environments that differ by country, and the importance of a corporate-wide strategy that leverages this diversity. However, it is evident that corporate-wide integrity is also necessary. The issue is in how to engender a sense of belonging in a part of a company while respecting varied values and behavioral norms on the basis of different business environments. One possible way is for the company to have a clear vision. However, a vision is an abstract concept, and companies must have clear overall objectives, regional centers, and overseas entities, and must also clarify assessment standards and decision-making processes as much as possible. In this regard, Japanese corporations have operated with corporate implicit knowledge on the basis of long-term employment relationships, and these corporations must consciously work on a multi-dimensional hybrid-style organization that includes overseas entities.

In addition, company flexibility is important in executing management strategies. Particularly for high-growth emerging countries, business environments are constantly changing, whereas global expansions are often long-term investments. Across all case studies included in this paper-Hitachi Construction Machinery, Shiseido, and Suzuki Motor-it took more than 10 years for a local entity to generate profit. These case studies examine China and India, prior to our now-flattened world; thus, the 10-year figure must not be taken too seriously. However, overseas expansions must certainly be implemented as a long-term perspective than as a new domestic business. Long-term investment in a highly uncertain world requires highly flexible strategies from the perspective of risk management. In that regard, companies take a flexible approach to partnerships with local companies rather than attempting to do business on their own. In addition, having a long-term strategy is important, but companies must have the flexibility to change strategies in response to great changes in business conditions. Success stories of the past depend on a company's core competencies; however, in times of volatile change in business environments, it likely that these will lead to core rigidities (Leonard-Barton 1992). Further, it is clear that, in Japan, the management policies used in the past are not appropriate for emerging countries with vastly differing business environments. For business managers, an era that demands free and flexible thinking has arrived.

Open Access This chapter is distributed under the terms of the Creative Commons Attribution Noncommercial License, which permits any noncommercial use, distribution, and reproduction in any medium, provided the original author(s) and source are credited. 


\section{References}

Asakawa, K. (2011, October). Global R\&D management. Tokyo: Keio University Publishing Co.

Barney, J. B. (1986). Strategic factor markets. Management Science, 32, 1231-1241.

Barney, J. B. (1991). Firm, resources and sustained competitive advantage. Journal of Management, $17,99-120$.

Bartlett, A. C., \& Ghoshal, S. (1989). Managing across borders: The transnational solutions. Boston: Harvard Business Press.

Doz, Y., Santos, J., \& Williamson, P. (2001). From global to metanational: How company win in the knowledge economy. Boston: Harvard Business School Press.

Kogut, B., \& Zander, U. (1992). Knowledge of the firm, combinative capabilities, and the replication of technology. Organization Science, 3(3), 383-397.

Kogut, B., \& Zander, U. (1993). Knowledge of the firm and the evolutionary theory of the multinational corporation. Journal of International Business Studies, 24, 625-645.

Leonard-Barton, D. (1992). Core capabilities and core rigidities: A paradox in managing new product development. Strategic Management Journal, 13, 111-125.

Motohashi, K. (2011, August). Measuring multinational's $R \& D$ activities in China by patent database: Comparison of European. Japanese and US firms, a paper presented at Academy of Management conference, San Antonio.

Porter, M. E. (1980). Competitive strategy: Techniques for analyzing industries and competitors. New York: Free Press. 